\title{
LOS BANŪ BURUNŶ̄̄L, UNA FAMILIA DE INTELECTUALES DENIENSES
}

\author{
a Marra Jesús, con mi \\ admiración y afecto \\ Mahmūd 'Alī MAKKĪ \\ Universidad de El Cairo
}

Entre las familias levantinas cuyos miembros destacaron en las ciencias religiosas, merece citarse la de los Banū Burunŷāl o Berenŷāl. A lo largo de dos siglos, desde mediados del siglo XI hasta mediados del XIII, se conocen miembros de esta familia que cultivaron las ciencias religiosas: lecturas alcoránicas, jurisprudencia, tradiciones (hadt), misticismo, etc. Algunos de ellos desempeñaron altos cargos judiciales y todos gozaron de gran prestigo. Eran vecinos de la ciudad de Denia, pero sus actividades se desarrollaron en toda la región levantina y especialmente en Valencia.

Llama la atención la terminación -âl en el apellido de esta familia, evolución del ellus latino. En su valioso estudio de los apellidos árabeespañoles, D. Francisco Codera observa que la citada terminación era abundante en Valencia y Cataluña ${ }^{1}$. El mismo arabista nos ofrece un largo repertorio de apellidos con la terminación $-a l o-l l$, sacados de los diccionarios biográficos incluidos en la Biblioteca Arábico-Hispana ${ }^{2}$. Se trata de un sufijo usado por los mozárabes en forma de el o elo, para formar el diminutivo, y adoptado por los musulmanes españoles.

${ }^{1}$ Cf. Francisco Codera, Discursos leidos ante la Real Academia Española en su recepción pública, el día 15 de mayo de 1910, Madrid, 1910, p. 25.

${ }^{2}$ Op. cit., pp. 55-57. 
Los apellidos que tienen esta terminación pueden dividirse en dos grupos. El primero incluye nombres romances de origen totalmente latino, tales como Barțāl, que llevaba un primo materno del célebre Almanzor, llamado Muhammad b. Yahyà b. Zakariyyā' (m. 394/1004), cadí mayor de Córdoba ${ }^{3}$. El apellido procede del Bajo Latín, pardalus; en español, pardal (=gorrión) ${ }^{4}$. Otro apellido con la misma terminación es Muŷuāl, que llevaban varios juristas valencianos, entre ellos "Abd Allāh b. Ibrāhīm al-'Abdarî y 'Abd Allāh b. Ahmad b. Sa'īd'. Según Simonet, el nombre es probablemente un diminutivo de mauch, en el sentido de mochuelo, ave? . Pertenece al mismo grupo el apellido

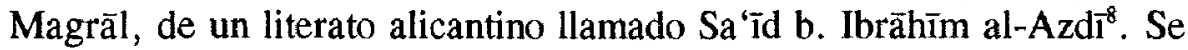
trata de un diminutivo de origen latino, macer ("flaco", "enjuto"), del que procede el castellano magro".

El otro grupo es el híbrido, es decir, el de los apellidos árabes con el sufijo romance -ăl. Como ejemplos de estos apellidos, citamos el de Jadriyāl, diminutivo de ajdar ("verde"), que llevaban dos tradicionistas: Muhammad b. Ibrāhīm al-Jazraŷī, de Quesada ${ }^{10}$ y Muhammad b. Ahmad al-Jazrâŷ1', así como el de 'Amrāl, diminutivo de 'Amr, de un tal Muhammad ibn Ahmad, de Almería'

${ }^{3}$ Cf. su biografía en Ibn al-Faradī, n. 1388, II, p. 107, y al-Nubāhī, Marqaba, p. 84. Llama la atención que este personaje era de ascendencia puramente árabe, de la tribu de Tamīm, pese a su apellido romance.

${ }^{4} C f$. F. Simonet, Glosario, pp. 424-425. En este sentido de "gorrión" aparece el nombre barțal (pl. barạtili) más de una vez en el dîuãn de Ibn Quzmän.

${ }^{5}$ Cf. Ibn al-Abbār, Takmila, ed. Codera, no 1386, p. 481.

${ }^{6} C f$. Ibn al-Abbär, $M u$ ŷam, no 207, p. 226.

${ }^{7}$ Glosario, p. 351.

${ }^{8}$ Cf. Ibn 'Abd al-Malik al-Marrākušn, al-Dַayl wa-l-takmila, t. IV, no 50, p. 23.

${ }^{9}$ Glosario, p. 325.

${ }^{10} C f$. Ibn al-Abbär, Takmila, ed. Codera, ñ 695, p. 203, y Mu'yam, no 149 , p. 166. 624.

${ }^{11} C f$. Ibn 'Abd al-Malik al-Marräkuši, al-Dayl wa-l-takmila, V, $\mathrm{n}^{\circ} 1185$, p.

${ }^{12}$ Cf. Ibn 'Abd al-Malik, op.cit., n' 50, p. 23. 
El apellido Barunȳāl o Burunȳāl, así vocalizado por Ibn alAbbār ${ }^{13}$, pertenece al primer grupo, es decir a los que son enteramente de origen latino o romance. Francisco Simonet ${ }^{14}$ dice que corresponde a Baronchel o Boronchel que, a su vez, proceden de Barunculus o Baroncellus (parvus baro), del bajo latín. Se adoptaron otras formas del mismo origen utilizadas en Italia, Francia y sobre todo en Cataluña y Levante: Berengello, Berenguillo, Beringuel y Berenguer. Este último apellido lo llevaron algunos condes de Barcelona, desde el primero, Ramón Berenguer I (1018-1035) hasta el cuarto que llevaba el mismo nombre y apellido (1137-1162).

El primero que conocemos de los Banū Burunyāal o Berenguel es un tal Abū "Alī al-Hasan b. Jalaf b. Yahyà al-Umawī, de Denia. El gentilicio al-Umawī indica que pertenecía a los Omeyas, antiguos emires y califas de al-Andalus, pero no necesariamente descendientes directos de este noble linaje. Se sabe que los elementos cristianos que abrazaban el islam a manos de algún árabe podían llevar la misma nisba ("gentilicio") de sus patronos, calificándose de mawlà ("liberto") de sus amos. Creo que éste es el caso del citado al-Hasan b. Jalaf, que nació en Denia en una fecha no determinada, pero, según parece, alrededor de mediados del siglo XI. Realizó un viaje a Oriente, donde, cumplida la peregrinación a los Santos Lugares, asistió a las clases de algunos maestros en Alejandría, Jerusalén y Escalón. Allí estudió la obra de Ibn al-Anbārī titulada $A l$-waqf wa-l-ibtidă', una de las básicas para el conocimiento de las lecturas alcoránicas ${ }^{15}$. Su permanencia en Oriente duró cuatro años, entre 1072 y 1076. Tras su regreso a Denia, fue

${ }^{13}$ Cf. Mu'yam, p. 127.

${ }^{14}$ Glosario, p. 137.

${ }^{15}$ Para la biografía de Ibn al-Anbārī (m.328/940) véase al-Zubaydī, Țabaqãt

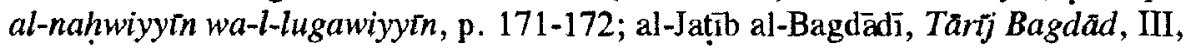
181-186; Yāqūt, Iršad al-artb, ed. El Cairo, XVIII, 306-313; C. Brockelmann, Geschichte, II, 214-216 (trad. ár.). Se sabe que Denia fue uno de los centros más importantes de los estudios relativos a las lecturas alcoránicas. Una de las máximas autoridades en este terreno fue $A b \bar{u}$ 'Amr al-Dānī (m.444/1051), que no

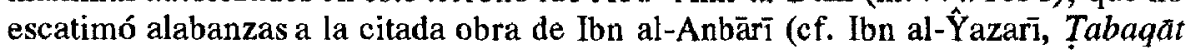
al-qurra', I, 231). 
nombrado cadr, lo que no le impidió dedicarse a la enseñanza. Su muerte acaeció alrededor del año $500 / 1107^{16}$.

De este personaje conocemos dos hijos. El primero, Abū l-'Abbās Ahmad, cuya breve biografía se limita a señalar que fue discípulo de un célebre tradicionista versado también en lecturas alcoránicas, llamado Abū Ŷa'far Ibn Gazlün, de Tudela (m. 524/1130) ${ }^{17}$. El otro hijo, de más renombre, fue Abū Bakr Muhammad, al que Ibn Baškuwāl e Ibn al-Abbār dedicaron detalladas biografías. Hizo un viaje a Oriente poco después de 1107. En Alejandría estudió con su compatriota Abū Bakr de Tortosa y adquirió una î́aza del célebre al-Gazāin, que le autorizaba a transmitir las obras del gran maestro oriental. A su regreso a alAndalus, asistio asiduamente, entre 1113 y 1115, a las clases del famoso Abū 'Alī al-Șadafī en Murcia, con el cual estudió un gran número de obras jurídicas, históricas, lexicográficas, místicas e importantes colecciones de tradiciones. Entre ellas Al-Muwatta' de Mālik, la Mudawwana de Sahnūn, al-Ŷami' y Šmā'il al-nabi de alTirmīđì, al-Sunan y al-'llal de al-Dāraquṭn̄, al-Tārị̉ de Ibn Abī Jaytama, las colecciones de tradiciones auténticas de al-Bujārī, Muslim y al-Bazzär, Garib al-hadț de Abū 'Ubayd sobre el léxico raro de las tradiciones y finalmente dos obras de iniciación mística: Adab al-suhba de al-Sulamī y Riyddat al-muta'allimin de Abū Nu'aym de Ispahān.

Los maestros que contribuyeron a la formación de Ibn Berenyāl fueron los más renombrados de al-Andalus. Se cuentan entre ellos Abū 1-Walīd Ibn Rušd (Averroes, el Abuelo), Ibn al-Munāṣif e Ibn 'Attāb. Ibn al-Abbār lo califica de "uno de los prohombres de al-Andalus en erudición e inteligencia. Se dedicó a la enseñanza de las ciencias alcoránicas y las tradiciones. Sus conocimientos eran variadísimos y su memoria, prodigiosa. Gozaba de gran prestigio entre los príncipes de su tiempo, quienes acudían frecuentemente a pedir su consejo". Cuenta Ibn al-Abbār que en una de sus visitas a Valencia, gobernada en aquel entonces por Yahyyà b. Gāniya, cayó enfermo. Al insistir en regresar a su pueblo, Denia, para recibir allí los cuidados médicos necesarios, Ibn 508.

${ }^{16}$ Cf. Takmila, ed. Codera, $\mathrm{n}^{\circ} 29$, p. 14, y al-Maqqarī, Nafh al-titb, II, 507-

${ }^{17}$ Cf. Al-Dayl wa-l-takmila, $\mathrm{I}, \mathrm{n}^{\circ} 106$, p. 91. 
Gāniya mandó que le acompañara un enfermero. Ibn Berenyâl recitó entonces el siguiente verso :

Deudos temo que al enterarse de lo que me ocurre,

Se echen a llorar, tanto los hombres jóvenes como las bellas mozas.

Poco después de su regreso a su Denia natal, falleció en rayab 536 $(=\text { febrero } 1142)^{18}$.

En su biografía, Ibn Baškuwāl inserta una curiosa anécdota que pone en boca de un literato egipcio, maestro suyo, llamado Abū l-Hasan al-Sa'īdī. Dice :

En mi vida hubo un año en que perdí todos los medios de vivir. Eso a pesar de que sabía de memoria la obra de gramática de Sỉbawayh titulada al-Kitäb, además de otras obras básicas de literatura. Llegué a pensar que me había alcanzado la mala suerte que suele acompañar a los hombres de letras. Se me ocurrió entonces componer un poema panegírico en petición de socorro al gobernador de "Aydäb". Preparé unas hojas y el tintero y esperé hasta la madrugada, pero no se me ocurrió nada. Al final, Dios hizo que mi pluma escribiera los siguientes versos:

Me dijeron: atrae a ti los corazones de la gente;

y contesté: más compasivo que la gente es el Creador de la gente.

Si yo estuviera seguro de la utilidad de mi solicitud, a ellos acudiría gustoso.

Pero un hombre como yo, pidiéndole favores a la gente, sería como el perro que está acechando un descuido del pastor.

¿Cómo tiendo mi mano a pedir, si la desesperación la obliga a cerrarse?

Más vale el abandono a la voluntad de Dios, que besar las manos ajenas, sean caritativas o despiadadas.

${ }^{18}$ Cf. Ibn Baškuwāl, no 1287, p. 553-554; al-Dabbī, Bugya, ed. El Cairo, $\mathrm{n}^{\circ}$ 91, p. 70; Ibn al-Abbār, Mu'yam, no 117, pp. 127-129; al-Marrākušì, Al-Dayl wa-l-takmila, VI, $\mathrm{n}^{\circ} 430$, p. 160.

19 'Aydāb era un puerto del extremo sur de la costa occidental del Mar Rojo. Por este puerto pasaban los peregrinos y comerciantes procedentes del Alto Egipto, hacia el puerto de Adén y demás puertos del Yemen. Llegó a ser emporio comercial de cierto esplendor y opulencia, entre el siglo X y el XIII. Véase Yäqūt, $M u^{\prime}$ ŷam al-buldän, IV, 171. 
Al componer estos versos, se sosegó mi alma, sentí confianza y familiaridad con lo divino. Di gracias a Dios por haberme hecho desistir de pedir favores a una criatura como yo. Apenas pasaron tres días cuando recibí un decreto del gobernador de 'Aydāb en el que me nombraba cadí de todo el Alto Egipto y más tarde añadiendo la provincia de Ijmīm. Luego me honró con el título de Cadí Mayor ( $\left.q d d r l-q u d \tilde{a}^{*}\right)$ y con esto mi pobreza se trocó en opulencia y bienestar.

Abū Bakr Muhammad tuvo dos hijos. El primero es Abū l-Hasan 'Ali, que hizo un viaje a Oriente. En Alejandría asistio a las clases del famoso maestro Abū l-Tāhir al-Silafî. Al volver a su Denia natal, se dedicó a la enseñanza. Entre sus disć́pulos se cuenta el célebre Abū 1Rabī' b. Sālim de Valencia, maestro a su vez de Ibn al-Abbār. Abū lRabī precisa que asistía a las clases del deniense en el año 580 (11841185). Murió en una fecha no determinada ${ }^{20}$.

El otro hijo, Abū Ya'far Ahmad, venerable alfaquí, desempeñó el cadiazgo en Denia. Tanto por sus cualidades personales como por el prestigio de su familia, tenía gran ascendiente cerca de las autoridades de su pueblo. Murió en Denia en yumäda I del 586 (junio 1190) ${ }^{21}$.

El último miembro de los Berenŷāl es un hijo del que acabamos de biografiar, Abū l-Tayyib Sa'd b. Ahmad. Fue discípulo de su padre y de otros maestros, entre los cuales merece citarse el valenciano Abū lJațtāb Ibn Wāŷib. Escribió mucho y se dedicó, como sus antepasados, a la enseñanza. Falleció a principios del año 626 (1228), es decir unos diez años antes de la caída de Denia en manos de Jaime I el Conquistador (16 de safar $636=28$ de septiembre 1238).

A continuación ofrecemos un cuadro genealógico de los Banū Barunŷāl o Berenŷāl de Denia, de acuerdo con los datos biográficos que acabamos de exponer.

${ }^{20}$ Cf. Takmila, ed. M. Alarcón y A. González Palencia, n ${ }^{\circ} 2342$, p. 228.

${ }^{21}$ Cf. Takmila, ed. Codera, I, 86; Al-Dayl wa-l-takmila, I, no 599, p. 408. 


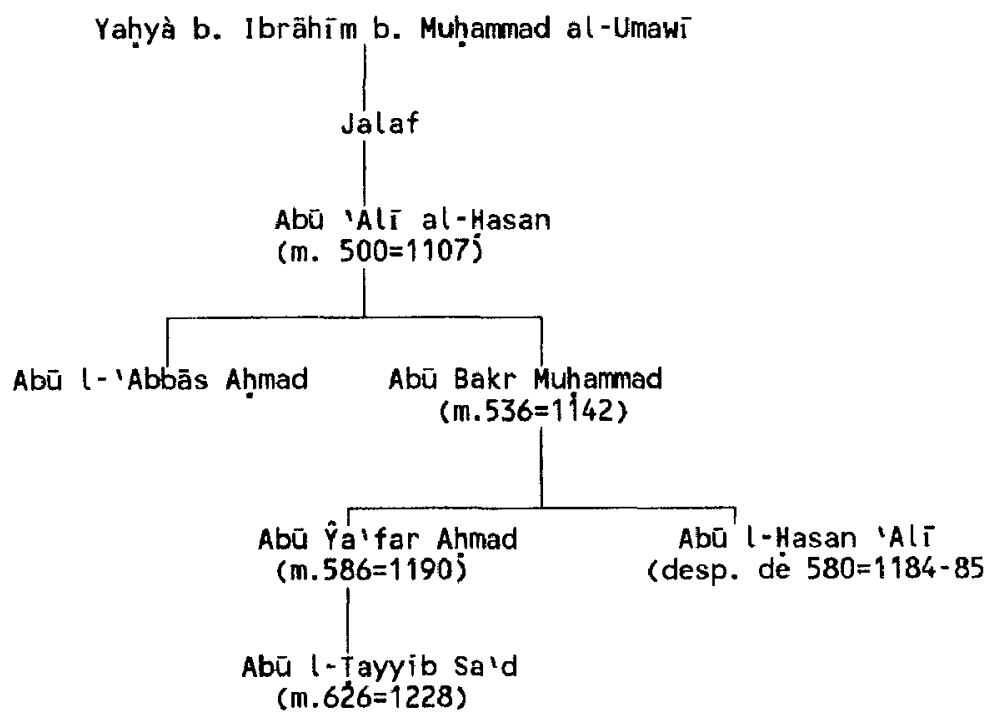

Una advertencia final que, a primera vista, podría parecer, al lector de este modesto trabajo, nacida de una fantasía. Hemos seguido la trayectoria de los barunŷălíes o berenguelíes desde su aparición en el siglo XI hasta la reconquista de Denia por Jaime el Conquistador. En los diccionarios biográficos posteriores no encontramos indicios de que los descendientes de esta familia hayan emigrado a las regiones que aún quedaban en manos de los musulmanes en la Península o a los refugios norteafricanos, como harían otros miembros de familias principales de Levante. Probablemente esos descendientes habrían quedado en su patria levantina en calidad de mudéjares y - ¿quién sabe?- más tarde, pasadas varias generaciones, en calidad de moriscos, sobre todo tratándose de una familia como ésta, que pertenecía a la aristocracia social y a la élite intelectual. Puede pensarse que descendientes de los Berenŷalíes, amparados en su ilustre apellido romance que llevaban nada menos que los condes de Barcelona, sobrevivirían hasta el siglo XVI, tras convertirse en cristianos nuevos. 
$Y$ digo esto porque me parece que Miguel de Cervantes, el príncipe de las letras hispánicas, podría haberse inspirado en el apellido de esta familia deniense cuando presumio que fuera un tal Cide Hamete Benengeli el coautor de su inmortal obra, Don Quijote de la Mancha. Entre el apellido real de la familia levantina y el del presunto autor morisco, la diferencia es mínima. Incluso notamos que trocando el Benengeli en Berengeli, Cervantes pone jocosamente en boca de Sancho Panza la relación entre el apellido del sabio moro y las berenjenas a las cuales eran aficionados los moriscos. Yo no descarto la posibilidad de que Cervantes, en sus andanzas por Levante y por su vecina La Mancha, o quizá durante su permanencia como recluso en el presidio de Sevilla, hubiera topado con un morisco, personaje real, llamado Berengeli, cuyo apellido le habría servido como fuente de inspiración al pretender, entre bromas y veras, atribuir la autoría de su "Quijote" a un sabio morisco. Por otra parte, sabemos que en tiempo de Cervantes la región de Levante y La Mancha, lo mismo que Toledo, donde pretende haber encontrado los cartapacios con los originales de su novela, estaban pobladas de moriscos. El caso del moro Ricote, amigo de Sancho Panza, es asaz significativo.

Todo esto podría ser fruto de una imaginación desaforada, pero aún así, no tengo inconveniente en exponerlo, porque quizás otras investigaciones demuestren que algo de verdad yace debajo de esta hipótesis. 